\title{
Current Drug Pricing Status in India
}

\section{Sandeep Narula*}

The IIHMR University, Jaipur, India

The drug prices in India are controlled using what is called the Drugs (Prices Control) Order (DPCO). The DPCO is an order issued by the government under Section 3 of the Essential Commodities Act, 1955 empowering it to fix and regulate the prices of essential bulk drugs and their formulations. NPPA (National Pharmaceutical Pricing Authority), Controls and regulates the prices of Pharmaceutical drugs in India, it has limited authority to fix, review and justify pharmaceutical prices under the Drug Prices Control Order (DPCO), 1995. NPPA began working since August 1997. In order to fix and revise the prices of controlled drugs, the NPPA monitors the prices of decontrolled drugs in order to keep them at a reasonable level. The current DPCO 2013 has three primary aims: expanding the National List of Essential Medicines (NLEM), authorizing the National Pharmaceutical Pricing Authority

(NPPA) to regulate prices of India's NLEM, and authorizing the NPPA to regulate price increases of non-essential medicines.

The DPCO uses market-based mechanisms to set price ceiling (the ceiling price is decided by taking the simple average of prices of brands with more than $1 \%$ market share). In the case of each bulk drug, which is under price control a single maximum selling price is fixed that is applicable throughout the country and that is called as ceiling price. It works differently, depending on how many products are in a categoryThe categorization is done based on the number of competitors in that category- if there are many drugs in the same category then the price cap is calculated based on the average price of the available drugs which collectively have at least $1 \%$ market share in category (for which we want to calculate the price ceiling, this ceiling price does not include pharmacist margin) and if the drug is the "only" drug available in the product category then the price cap for that drug is the "fixed percent" and this fixed percent calculations are based on the price reduction done in similar drug categories, of the current drug price.

This market based pricing (MBP) move initiated by the Government of India is highly debatable and under has come under severe criticism from various Non-governmental organizations (NGOs).

The traditional cost base pricing method which is used more for regulating prices in India uses cost components like cost of API, cost of excipients, cost of duties applicable, cost of labour and overheads, and cost packaging material and then on this price the margins/profits are added. But even in this price method the issue of transfer pricing mechanism (method used mainly by MNC's) is under scanner. By various $\mathrm{NGO} / \mathrm{s}$ and $\mathrm{RTI}$ activists.

Although for essential category of medicines this method is still considered an appropriate method. Unfortunately Market based pricing has bearing with cost of medicine, directly it has no relation with cost of medicine; it is simply based on the competitors price prevailing in that therapeutic category. The following (Table 1) further proves my point that how the current market based pricing mechanism is making the drugs costly.

The MBP strategy is certainly not working in favour of common masses-there is strong demand that essential drugs should be sold under generic name- a strategy which India's neighbouring country is pursuing since last 3 decades and as per 2011 statistics the NMR
(Neonatal Mortality rate, per thousand live birth) of India and Bangladesh is 34 and 30 respectively; even the U5MR (Under five mortality rate, per thousand live births) of India and Bangladesh is 64 and 52 respectively.

Hence, in my opinion, Indian government should review the drug policy and should consider with a strong base to consider that pricing strategy which the society at large and makes healthcare accessible and affordable to the citizens.

\begin{tabular}{|l|l|l|l|l|}
\hline Drug & Disease & $\begin{array}{l}\text { Market based } \\
\text { pricing } \\
\text { (weighted } \\
\text { average) } \\
\text { (in Rupees) }\end{array}$ & $\begin{array}{l}\text { Market based } \\
\text { pricing } \\
\text { (Simple } \\
\text { average) } \\
\text { (in Rupees) }\end{array}$ & $\begin{array}{l}\text { Cost } \\
\text { based } \\
\text { pricing } \\
\text { (in } \\
\text { Rupees) }\end{array}$ \\
\hline Metformin & Diabetes & 33 & 45 & 14 \\
\hline Atorvastatin & High blood cholesterol & 142 & 127 & 17 \\
\hline Atenolol & High Blood pressure & 51 & 38.5 & 8 \\
\hline
\end{tabular}

(Source: Jan SwasthayaAbhiyaan (JSA))

Table 1: How the current market based pricing mechanism is making the drugs costly?

Corresponding author: Sandeep Narula, The IIHMR University, Jaipur, India, Tel: +918058760911; E-mail: sandeep@iihmr.edu.in

Received August 31, 2015; Accepted September 10, 2015; Published September 17,2015

Citation: Narula S (2015) Current Drug Pricing Status in India. Pharmacoeconomics 1: e101. doi:10.4172/pe.1000e101

Copyright: (c) 2015 Narula S. This is an open-access article distributed under the terms of the Creative Commons Attribution License, which permits unrestricted use, distribution, and reproduction in any medium, provided the original author and source are credited. 